\title{
Primer Biliyer Kolanjit Hastalarında Tiroid Otoimmünitesinin Değerlendirilmesi
}

\author{
Assessement Of Thyroid Autoimmunity In Primary \\ Biliary Cholangitis Patients
}

\section{Sezgin Vatansever', Zehra Betül Paköz², Süleyman Günay³, Altay Kandemir", Belkıs Ünsal'}

' Katip Çelebi Üniversitesi, Atatürk Eğitim ve Araşıırma Hastanesi, Gastroenteroloji Kliniği, İzmir

${ }^{2}$ Tepecik Eğitim ve Araştırma Hastanesi, Gastroenteroloji Kliniği, İzmir

${ }^{3}$ Atatürk Eğitim ve Araştırma Hastanesi, Gastroenteroloji Kliniği, İzmir

${ }^{4}$ Adnan Menderes Üniversitesi, Gastroenteroloji Bilim Dalı, Aydın

Yazışma Adresi / Correspondence:

Zehra Betül Paköz

Tepecik Eğitim ve Araştırma Hastanesi, Gastroenteroloji Kliniği, Konak-Izmir

T: +905055250509 E-mail: betulpakoz@yahoo.com

Geliș Tarihi / Received : 17.04.2018 Kabul Tarihi / Accepted : 28.07.2018

\footnotetext{
$\ddot{\mathbf{O z}}$

Amaç Primer biliyer kolanjit (PBK) sıklıkla diğer otoimmün hastalıklarla, özellikle de otoimmün tiroit hastalığı ile ilişkilendirilmektedir. Çalışmalar, otoimmün tiroid hastalğı ve anti-tiroid antikorlarının prevalansinın PBK'de \%14-24 olduğunu göstermiş̧ir. Bu çalışmanın amacı, PBK'li hastalarda eşlik eden tiroid otoimmünitesini ve diğer tiroid hastalkklarıı araş̧ırmaktır. (Sakarya Tip Dergisi, 2018, 8(3):511-517)

Gereç ve Bu kesitsel ve tanımlayıcı çalışma, Haziran 1999 ile Aralık 2017 tarihleri arasında üçüncü basamak gastroenteroloji bölümünde tedavi edilen

Yöntem 263 PBK hastasının tıbbi dosyalarından alınan verilere dayanmaktadır. Tiroid otoimmünitesi, normal aralığın üzerinde anti TPO ve/veya anti TG şeklinde tanımlanmaktadır. Otoimmün tiroid hastalığı olan ve olmayan PBK hastalaıının klinik özellikleri ve laboratuvar bulgularındaki farklılıklar kaydedilmiştir.

Bulgular Tiroid otoimmünitesi, serimizdeki 80 hastada (\%30.4) saptandı. Hashimato tiroiditi 47 hastada tespit edildi. Otoimmun tiroid hastalığı olan grupta hipertiroidi olan iki hastanın birinde Graves hastalı̆ı, diğerinde ise Hashimato hastalığı olduğu belirlendi.

Otoimmün dışı tiroid hastalıkları grubunda 19 hasta mevcuttu. Bu hastaların 15 'inde multinodüler guatr, 3 'ünde toksik tiroid nodül ve bir hastada tiroid kanseri vardı. Otoimmün dışı tiroid hastalı̆ı̆ grubunda 9 hastada hipertiroidi saptandı. Hipertiroidi olan hastaların 3 'ünde toksik tiroid nodülü, 1'inde akut tiroidit ve 5'inde diğer tiroid hastalıkları mevcuttu. Toksik tiroid nodülü olan bir hastada tiroid papiller mikrokarsinom olduğu saptandı. Aşikar tiroid hastalığı olmayıp anti-tiroid antikorları pozitif olan 9 hasta mevcuttu. Çok değişkenli regresyon analizinde ANA pozitifliği olması (OR 1.8, 95\% Cl 1.04-3.28; p<0.036) tiroid otoimmunitesi için bir risk faktörü olduğu saptandı.

\section{Abstract}

Objective $\quad$ PBC is frequently associated with other autoimmune diseases, especially with auto-immune thyroid disease. Studies showed $14-24 \%$ prevalence of autoimmune thyroid disease and anti-thyroid antibodies vary considerably in primary biliary cholangitis (PBC). The aim of the present study was to investigate thyroid autoimmunity in patients with PBC. ( Sakarya Med J, 2018, 8(3):511-517 ).

Materials and This study was based on data derived from the medical files of 263 consecutive PBC patients treated in the gastroenterology department Methods of our tertiary care center between June 1999 and Aug 2017. Thyroid autoimmunity was defined as Anti TPO and/or Anti TG above the normal range. The differences in clinical features and laboratory findings of PBC patients with and without autoimmune thyroid disease were documented.

Results The average age was 55.0 $\pm 12.4(28-84)$ and $244(92,7 \%)$ patients were female. Thyroid autoimmunity was evident in 80 patients $(30,2 \%)$ of our series. There were 19 patients in non- autoimmune thyroid diseases group, 15 patients with multinoduler goiter, 3 patients with toxic thyroid nodul and one patient with thyroid cancer. We found 9 hyperthyroid patients in non-thyroid autoimmunity group, 3 patients with toxic thyroid nodul, one patient with acute thyroiditis and 5 patients with other thyroid diseases. One patient who had toxic thyroid nodul was determined as thyroid papillary microcarcinoma.

Conclusion Thyroid autoimmunity is frequently seen in PBC patients. There were no significant clinical parameters differences in our study. However, patients with PBC should be screened for thyroid disease. 
Sakarya TIp Dergisi 2018;8(3):511-517

VATANSEVER ve ArK. Primer Biliyer Kolanjitte Tiroid Otoimmünitesi

\section{Giriş}

Primer biliyer kolanjit (PBK), küçük safra kanallarında hasarın eşlik ettiği, etiyolojisi bilinmeyen, yavaş ilerleyen kolestatik granülomatöz bir karaciğer hastalığıdır'. PBK sıklıkla başka otoimmün hastalıklar ile ilişkilidir ve bunlardan en yaygın olanı otoimmün tiroid hastalığıdır (ОіTH $)^{2,3}$. OiTH'nin tahmini prevalansı \%5'tir ve klinik anlama sahip olmayan anti-tiroid antikorlarının prevalansı daha da yüksek olabilir ${ }^{4,5}$. Tiroid otoimmünitesi (OіTH veya izole anti-tiroid antikor pozitifliği) ile diğer otoimmün bozukluklar arasındaki ilişki yaygın bir şekilde raporlanmıştır ${ }^{4}$. PBK'de tiroid hastalığının prevalansı \%7.2 ila \%14.4 arasında bildirilmiştir ${ }^{3}, 6-8$ ve otoimmün tiroiditi insidansı \%14.4-\%23.8 bulunmuştur $^{9-13}$. Eşzamanlı tiroid hastalığının varlığı ve klinik bulgularının, PBK hastalarının takibinde önemli klinik yansımaları olabilir ${ }^{14}$. Hipotiroidinin daha fazla yorgunluk ile ilişkili olduğu bilinmektedir. ${ }^{15}$ Diğer ekstrahepatik hastalıklar gibi tiroid fonksiyon bozukluğunun kontrolü de yaşam kalitesini önemli ölçüde artırabilir.

Bu çalışmada, PBK hastalarındaki tiroid otoimmünitesi ve özelliklerinin araştıııması amaçlandı.

\section{Yöntem}

Bu kesitsel ve tanımlayıcı çalışmada veriler, hastanemizde Haziran 1999 ile Aralık 2017 arasında takip edilen 263 PBK'lı hastanın hastane kayıtlarından elde edildi.

Tüm hastaların yaşı, hastalık süresi, tiroid bozuklukları öyküsü, ilişkili hastalıkları ve hastalık şiddetini içeren ayrıntılı bir öykü alındı. PBK'nin yorgunluk, kaşıntı ve sağ üst kadran ağrııını içeren başIıca semptomlar yüzdesel olarak gruplandırıldı. Hastalar ekstrahepatik hastalık bulguları açısından sorgulandı. Hastalarda ekstrahepatik hastalık için pozitif bulgular bulunduğu takdirde ileri tetkikler yapıldı.

PBK tanısı üç kriterden ikisinin varlığı ile konuldu; $>6$ ay kolestatik karaciğer hastalığı laboratuvar bulguları olması, anti-mitokondriyal antikor pozitifliği ve karaciğer biyopsisinin PBK ile uyumlu olması ${ }^{14}$. Diğer kolestatik karaciğer hastalıkları olan hastalar çalışma dışı tutuldu. Hastaların 65 'ine karaciğer biyopsisi yapılmadı. Aşikar siroz bulguları olan ve biyopsi yapılmayan 52 hastanın 12'sinde otoimmün tiroid hastalığı ve 40 'ında otoimmün dışı tiroid hastalğı vardı. Histolojik evreleme Scheuer sınıflandırmasına göre yapıld ${ }^{16}$.

Her hastaya ursodeoksikolik asit (10-15 mg/kg) verildi. Hastaların hiçbirinde alkol öyküsü yoktu. Bir hastada HBV enfeksiyonu da saptandı. Verileri yetersiz olan hastalar çalışmaya alınmadı.

Tiroid stimülan hormon (TSH), tiroksin (T4) ve tiroid otoantikorları ((tiroglobulin antikoru (anti-TG) ve tiroid peroksidaz antikoru (anti-TPO)) tüm olgularda ölçüldü.

Serum TSH (normal aralık 0.4-5.5 mlU/L) ve serbest T4 (FT4) (normal aralık 0.89-1.72 ng/d) ölçümleri için kemilüminesans immünometrik tayin kullanıldı. TSH için referans aralık $0.01 \mathrm{mIU} / \mathrm{L}$ ila $250 \mathrm{mIU} / \mathrm{L}$ alınmıştır. Tiroid antikoru direkt RIA sistemi ile ölçülmüştür (normal aralık anti-TPO<57 $\mathrm{IU} / \mathrm{ml}$, anti-TPO için referans aralık 0-1300 mIU/L; normal aralık anti-TG $<60 \mathrm{IU} / \mathrm{ml}$, anti-TG için referans aralık 0-500 mlU/L). Ig M, nefelometrik teknik kullanılarak ölçülmüştür (normal aralık Ig $\mathrm{M}<304 \mathrm{mg} / \mathrm{ml}$ ). ANA, AMA ve ASMA, indirekt immünfloresan ile substrat olarak fare böbreği ve midesi kullanılarak ölçülmüştür. 1/40 üzeri titre pozitif kabul edilmiştir. Tüm otoantikor testleri 
kurumumuzda aynı laboratuvar tarafından gerçekleştirilmiş̧ir.

Tiroid otoimmünitesi, normalden yüksek Anti TPO ve/veya Anti TG olması şeklinde tanımlandı. Hashimato tiroiditi (1) hipotiroidizm (TSH>4 mlU/L; (2) tespit edilebilir anti TPO ve/veya anti TG; (3) ve/veya ultrasonografik incelemede tiroidin ekojenitesinde azalma olması olarak tanımlandı 17 . Graves hastalığı tanısı hipertiroidizm ve klinik özellikler ile konuldu. Graves Hastalığı tanısı hipertiroidizm ve klinik özellikler ile doğrulanamadığı takdirde TSH reseptör antikoruna bakıldı. Tiroid fonksiyon bozukluğu olan hastalara USG yapıldı ${ }^{18}$.

\section{İstatistiksel analiz}

İstatistiksel analizler IBM SPSS İstatistik 22 programı kullanılarak gerçekleştirildi. Hastaların kategorik dağılımları için Pearson Ki-kare testi ve Fisher kesin testi, bağımsız örnekler için Student T testi ve normal olmayan dağılımlar için Mann Whitney U testi kullanıldı. Bulgular, kategorik değişkenler için yüzde ve sıklık olarak ve sürekli değişkenler için, eğer değişken normal ise ortalama \pm std şeklinde verildi. Sapma değerleri, normal dağlım göstermedikleri takdirde ortanca (minimum maksimum) değerler olarak gösterilmedi. Lojistik regresyon analizi ile tirid otoimmunitesi için risk faktörleri belirlendi (\%95 güven aralıkları ile). P değeri 0.05 'in altında olduğunda istatistiksel anlamlı olarak kabul edildi.

\section{Bulgular}

Çalışmamızda, tanı anında ortalama yaş $54.7 \pm 12.5$ (28-84) yıl saptandı. Hastaların 243’ü (\%92.3) kadındı. Tiroid otoimmünitesi serimizdeki hastaların 80 'inde (\%30.4) saptandı. Semptomların analizi, demografik veriler ve laboratuvar verileri Tablo 1'de gösterilmektedir.

\begin{tabular}{|c|c|c|c|c|}
\hline $\begin{array}{l}\text { Hastaların } \\
\text { özellikleri }\end{array}$ & $\begin{array}{l}\text { Tüm hastalar } \\
(n=263)\end{array}$ & $\begin{array}{l}\text { Tiroidotoimmünitesi olan } \\
\text { hastalar }(\mathbf{n}=\mathbf{8 0})\end{array}$ & $\begin{array}{c}\text { Tiroid otoim- } \\
\text { münitesi olmayan } \\
\text { hastalar } \\
(n=183)\end{array}$ & $\mathbf{p}^{*}$ \\
\hline Ortalama yaş & $56.8 \pm 11.7$ & $54.8 \pm 12.1$ & $57.6 \pm 12.8$ & 0.099 \\
\hline $\begin{array}{l}\text { Tanı anında ortalama } \\
\text { yaş }\end{array}$ & $54.7 \pm 12.5$ & $52.9 \pm 11.9$ & $55.7 \pm 12.6$ & 0.097 \\
\hline Cinsiyet (K/E) & $243 / 20$ & $77 / 3$ & $167 / 16$ & 0.212 \\
\hline TSH (ulU/ml) & $1.7(0.001-68)$ & $2.4(0.001-68)$ & $1.6(0.01-24)$ & 0.003 \\
\hline FT4 (ng/dl) & $1.11 \pm 0.27$ & $1.07 \pm 0.3$ & $1.13 \pm 0.24$ & 0.078 \\
\hline Anti TPO (IU/ml) & $43(10-1300)$ & $248(19-1300)$ & $28(10-57)$ & $<0.001$ \\
\hline Anti TG (IU/ml) & $23(11-500)$ & $66.5(15-500)$ & $15(11-54)$ & $<0.001$ \\
\hline $\lg M$ & $320(51-1403)$ & $267(52-1160)$ & $353.5(51-1403)$ & 0.036 \\
\hline $\lg$ G $(\mathrm{mg} / \mathrm{dl})$ & $1717(200-4460)$ & $1640(200-4080)$ & $1802(941-4460)$ & 0.263 \\
\hline $\lg A(\mathrm{mg} / \mathrm{dl})$ & $252.5(40-800)$ & $246.5(85-603)$ & $254(40-800)$ & 0.819 \\
\hline \multicolumn{5}{|l|}{ Otoantikor } \\
\hline AMA & $88.0 \%$ & $80.0 \%$ & $86.8 \%$ & 0.153 \\
\hline ANA & $58.6 \%$ & $70.1 \%$ & $53.7 \%$ & 0.014 \\
\hline ASMA & $2.0 \%$ & $1.4 \%$ & $2.3 \%$ & 0.616 \\
\hline \multicolumn{5}{|l|}{ PBK aşaması } \\
\hline Erken evre (1 ve 2 ) & $124(\% 47.2)$ & $42(\% 52.5)$ & $82(\% 44,8)$ & 0.284 \\
\hline ileri evre (3 ve 4$)$ & $74(\% 28.1)$ & $25(\% 31,3)$ & $49(\% 26,8)$ & 0.46 \\
\hline Biyopsi yapılmayan & $65(\% 24.7)$ & $13(\% 16.2)$ & $52(\% 28.4)$ & 0.043 \\
\hline
\end{tabular}

Sakarya Tıp Dergisi 2018;8(3):511-517

VATANSEVER ve ArK. Primer Biliyer Kolanjitte Tiroid Otoimmünitesi 


\begin{tabular}{|l|c|c|c|c|}
\hline $\begin{array}{l}\text { Hastaların } \\
\text { özellikleri }\end{array}$ & $\begin{array}{c}\text { Tüm hastalar } \\
\mathbf{( n = 2 6 3 )}\end{array}$ & $\begin{array}{c}\text { Tiroidotoimmünitesi olan } \\
\text { hastalar (n=80) }\end{array}$ & $\begin{array}{c}\text { Tiroid otoim- } \\
\text { münitesi olmayan } \\
\text { hastalar } \\
(\mathbf{n = 1 8 3 )}\end{array}$ & p $^{*}$ \\
\hline $\begin{array}{l}\text { Otoimmün hastalık } \\
\text { ile birliktelik }\end{array}$ & $52(\% 19.8)$ & $16(\% 20)$ & $36(\% 19.7)$ & 0.951 \\
\hline Semptomlar & & & & \\
\hline Yorgunluk & $72.9 \%$ & $70.8 \%$ & $73.8 \%$ & 0.639 \\
\hline Kaşıntı & $61.0 \%$ & $56.9 \%$ & $69.1 \%$ & 0.393 \\
\hline $\begin{array}{l}\text { Sağ üst kadran } \\
\text { ağrıSı }\end{array}$ & $36.1 \%$ & $42.3 \%$ & $33.1 \%$ & 0.187 \\
\hline
\end{tabular}

*Tiroid otoimmünitesi olan ve olmayan hastaların karşılaştııııması

TSH: tiroid stimülan hormon, fT4: serbest tiroksin 4, anti-TPO: tiroid peroksidaz antikoru, anti-TG: tiroglobulin antikoru, Ig M: immünglobulin M, Ig G: immünglobulin G, Ig A: immünglobulin A, AMA: anti-mitokondriyal antikor, ANA: anti nükleer antikor, ASMA: anti düz kas antikoru

Tiroid otoimmünitesi saptanan grupta tiroid hastalı̆ı 52 hastada belirlendi. Hashimato tiroiditi 47 (\%17.8) hastada bulundu. Hashimato tiroiditi, 47 hastanın 14'ünde (\%29.7) PBK tanısı ile aynı zamanda veya sonrasında tespit edilirken, 32 hastada (\%68) PBK teşhisinden önce saptandı. Tiroid otoimmünitesi saptanan ve hipertiroidisi olan iki hastanın birinde Graves hastalı̆ı ve diğerinde Hashimato hastalığı vardı. Hastaların 28 'inde ise herhangi bir tiroid hastalığı bulguları olmaksızın Anti-TPO ve veya Anti-TG pozitifliği saptandı.

Ondokuz hastada otoimmün dışı tiroid hastalığı saptandı. Bu hastaların 15 'inde multi-nodüler guatr, 3 'ünde toksik tiroid nodülü ve birinde tiroid kanseri saptandı. Toksik tiroid nodülü olan bir hastada ameliyat edildiğinde tesadüfi olarak tiroid papiller mikrokarsinom saptandı.

IgM düzeyleri tiroid otoimmünitesi olan grupta, olmayanlara göre anlamlı olarak daha düşük bulundu ( $p=0.036)$.

Anti TPO ve anti TG pozitifliği, tiroid otoimmünitesi olan grupta, otoimmün dışı tiroid hastalığı olanlar grubuna kıyasla anlamlı olarak daha yüksek saptandı (95,9\% \& $0 \%$; $p<0,001) ;(54,3 \%$ \& $0 \% ; p<0,001)$.

Tiroid hastalıkları ve tiroid fonksiyonları Tablo 2'de gösterilmektedir.

\begin{tabular}{|c|c|c|c|c|}
\hline & Tablo 2. PBK hastalarında Tiroid hastalığı ve tiroid fonksiyon bozukluğu & \multicolumn{1}{|c|}{ p $^{*}$} \\
\hline & $\begin{array}{c}\text { Tüm hastalar } \\
(\mathbf{n = 2 6 3 )}\end{array}$ & $\begin{array}{c}\text { Tiroidotoimmünitesi olan } \\
\text { hastalar (n=80) }\end{array}$ & $\begin{array}{c}\text { Tiroid otoimmünitesi } \\
\text { olmayan hastalar } \\
(\mathbf{n = 1 8 3 )}\end{array}$ & \\
\hline Tiroid hastalığı & & $47(\% 58.7)$ & $0(\% 0)$ & $<0.0001$ \\
\hline Hashimoto tiroiditi & $47(\% 17.8)$ & $1(\% 1.3)$ & $0(\% 0)$ & 0.304 \\
\hline Graves hastalığı & $1(\% 0.4)$ & $3(\% 3.8)$ & $15(\% 8.2)$ & 0.288 \\
\hline Multinodüler guatr & $18(\% 6.8)$ & $1(\% 1.3)$ & $3(\% 1.5)$ & 0.999 \\
\hline Toksik nodül & $4(\% 1.5)$ & $0(\% 0)$ & $1(\% 0.5)$ & 0.999 \\
\hline Tiroid kanseri & $1(\% 0.4)$ & $28(\% 35)$ & $0(\% 0)$ & $<0.0001$ \\
\hline $\begin{array}{l}\text { Anti-TPO/Anti-TG } \\
\text { pozitifliği }\end{array}$ & $28(\% 10.6)$ & & & \\
\hline
\end{tabular}




\begin{tabular}{|l|c|c|c|c|}
\hline & $\begin{array}{c}\text { Tüm hastalar } \\
(\mathbf{n = 2 6 3 )}\end{array}$ & $\begin{array}{c}\text { Tiroidotoimmünitesi olan } \\
\text { hastalar (n=80) }\end{array}$ & $\begin{array}{c}\text { Tiroid otoimmünitesi } \\
\text { olmayan hastalar } \\
(\mathbf{n = 1 8 3 )}\end{array}$ & $\mathbf{p}^{*}$ \\
\hline Tiroid fonksiyonu & & & $9(\% 4.9)$ & 0.512 \\
\hline Hipertiroidi & $11(\% 4.2)$ & $2(\% 2.5)$ & $165(\% 90.2)$ & $<0.0001$ \\
\hline Ötiroidi & $208(\% 79.1)$ & $43(\% 53.8)$ & $9(\% 4.9)$ & $<0.0001$ \\
\hline Hipotiroidi & $44(\% 16.7)$ & $35(\% 44.8)$ & \\
\hline
\end{tabular}

Tablo 3. PBK tanılı hastalarda tiroid otoimmünitesi üzerine etkili faktörlerin çoklu değişken analizi

\begin{tabular}{|l|c|c|c|c|c|}
\hline & & & & \multicolumn{2}{|c|}{ Eksp. (B) için \%95 GA } \\
\hline Yaş & $\mathrm{B}$ & $\mathrm{p}$ & $\operatorname{Exp}(\mathrm{B})$ & Alt & Üst \\
\hline ANA & -0.013 & 0.222 & 0.987 & 0.966 & 1.008 \\
\hline Cinsiyet (kadın) & 0.614 & 0.036 & 1.848 & 1.041 & 3.283 \\
\hline ANA: anti nükleer antikor & 1.058 & 0.170 & 2.879 & 0.636 & 13.037 \\
\hline
\end{tabular}

\section{Tartışma}

Bizim çalışmamızda PBK'de tiroid otoimmünitesinin prevalansı \%30.4, PBK'de Hashimoto tiroiditinin prevalansı \%17.8 bulundu. Tiroid hastalıkları PBK'de en sık görülen ekstrahepatik tablolardan biridir. Çoğu, otoimmün tiroidit şeklinde görülmektedir. Tiroid otoimmünitesi, tiroid antijenlerine karşı tiroid antikorlarının, özellikle anti TG ve anti TPO'nun varlığında meydana gelmektedir. Sağıkılı popülasyonda bile tiroid hastalığı olmayan birçok bireyde pozitif anti TG ve anti TPO antikorların görülebileceği bildirilmiştir ${ }^{19}$. Çalışmalarda OiTH'nin prevalansı \%5 civarındadır, fakat anti-tiroid antikorların varlığı \%13 olarak saptanmıştı ${ }^{7,20}$. Pozitif tiroid antikorları olan hastalar için aşikar hipotiroidizmin yıllık insidansı \%2.9-5 bulunmuştur ${ }^{21}$. Başlangıç pozitif tiroid antikorları gelecekteki aşikar hipotiroidizm için erkeklerde 25 (\%95 GA: 10-63) ve kadınlarda 8 (\%95 GA: 5-15) kat artış olmaktadır ${ }^{22}$. Normal popülasyonda antikor pozitifliği yaş ile korele olduğu saptanmıştır ${ }^{23}$.

Crowe ve arkadaşları, PBK hastalarının 25/95'inde (\%26) pozitif tiroid antikorları bildirmiştir ${ }^{6}$. Başka bir çalışmada, Floreani ve ark. PBK hastalarında tiroid hastalığı birlikteliğinin, Hashimoto tiroiditi olan 94 hasta (\%10.2) dahil olmak üzere \%16.3 (150/921) olduğunu bildirmiştir ${ }^{24}$. Watt ve arkadaşları 160 PBK hastasında 37 tiroid hastası saptamışlardır. Bu hastaların \%43’ünde PBK saptanmadan önce tiroid hastalıkları gelişirken, \%57 hastada PBK tanısı ile aynı zamanda veya tanı sonrasında tiroid hastalıkları saptanmışıı ${ }^{25}$. Benzer şekilde başka bir çalışmada, otoimmün tiroid hastalığı PBK'li hastalarda \%11.5 olarak bildirilmiştir².

Bazı çalışmalarda tiroid antikoru varlığı infertilite, vasküloplasental komplikasyonlar, bazı kanser türleri, meme kanseri üzerinde pozitif prognostik etki ve yaşlı kadınlarda pozitif sağık etkisi ile ilişkilendirilmiştir ${ }^{27-30}$. Diğer yandan başka bir çalışmada tiroid antikoru, tiroit fonksiyonundan bağımsız olarak kemik kırığı artışı ile bağlantılı bulunmuştur ${ }^{31,32}$. Çalışmamızda tiroid antikorları ile semptomlar ve ekstrahepatik manifestasyonlar arasında anlamlı ilişki saptanmamıştır.

Ortak otoimmün mekanizma nedeniyle, PBK'e eşlik eden çeşitli otoimmün hastalıklar bulunmuştur 33.Yakın zamanda tamamlanan GWAs, OіTH'de de baskın risk geni olan STAT4 ile PBK arasında anlamlı bir korelasyon bildirmiştir ${ }^{34,35}$. Doğal veya adaptif immünitede görev alan genlerin poli-
Sakarya Tip Dergisi

2018;8(3):511-517

VATANSEVER ve ArK. Primer Biliyer Kolanjitte Tiroid Otoimmünitesi 
Sakarya TIp Dergisi 2018;8(3):511-517

morfizmleriyle ilişkiler de bildirilmiştir. Adaptif immün sistemin önemli bir regülatörü olan T lenfosit antijeni 4'ün (CTLA-4) ve tümör nekroz faktörü'nın (TNF) allelik varyasyonları, farklı otoimmün hastalıklara yatkınlık ile ilişkilendirilmiş ve ayrıca PBK ile de ilişkili bulunmuştur ${ }^{36,37}$.

Bizim çalışmamızda ekstrahepatik hastalık 55 (\%20.1) hastada tespit edildi. Ekstrahepatik hastalık varlığı iki grup arasında anlamlı şekilde farkılık saptanmadı $(p=0.951)$. Otoimmün hastalıkların kümelendiği bilinse de, Marina ve arkadaşları tiroid hastalı̆ı gelişiminin, birey bazında veya kolektif ele alındığında, takip zamanında diğer otoimmün bozuklukların varlığıla anlamlı ilişki içinde olmadığını bildirmiştir ${ }^{1,8,34}$. Bir çalışmada, $8 \pm 6.9$ ylllık takip sırasında hastaların \%61.2'sinde ekstrahepatik manifestasyonlar görülmüştür. Bunların \%20.4'ünde Hashimoto tiroiditi bulunmuştur3. Watt ve arkadaşları, 84/160 (\%53) PBK hastasında en az bir ek ekstrahepatik otoimmün durum olduğunu bildirmiş̧tir ${ }^{25}$. PBK'ye ekstrahepatik otoimmün hastalık ve tiroid otoimmünitesinin eşlik etmesi, kronik karaciğer hastalığı ile ilişkili komplikasyonları etkilememektedir ${ }^{3,24}$.

Bizim çalışmamızda, tanı zamanında tiroid fonksiyon bozukluğu olanlar ve olmayanlar arasında yorgunluk semptomu açısından anlamlı fark saptanmadı $(\mathrm{p}=0.669)$. Bu sonuç subklinik hipotiroid hastalarından veya tiroid fonksiyon bozukluğu için önceden alınan tedaviden kaynaklanıyor olabilir. Goldblatt ve arkadaşlarının çalışmasında, TSH düzeyleri bizim çalışmamızda olduğu gibi yorgunluk ile korelasyon göstermemiştir ${ }^{38}$. Benzer şekilde, Floreani ve arkadaşları da yorgunluğun iki grup arasında ilişkili olmadığını bildirmiştir ${ }^{24}$. Ek olarak, prurit ve sağ üst kadran ağrısı da tiroid otoimmünitesi ile ilişkilendirilmemiştir ${ }^{3,39}$.

Ekstrahepatik hastalık ile birlikte PBK'de kadın baskınlığı bildirilmiş olmakla birlikte bizim çalışmamızda tiroid otoimmünitesi olan hastalarda kadın baskınlığı gözlenmemiştir ${ }^{3,40}$. Bunun sebebi az sayıdaki erkek hasta olabilir.

Tiroid otoimmünitesi grubunda tanı zamanında ortalama yaş daha düşük olmakla beraber farklılık istatistiksel olarak anlamlı bulunmamıştır $(\rho=0.097)$. Yaş farkı, bazı hastaların tiroid hastalığı nedeniyle takip altında olmasından kaynaklanıyor olabilir.

Bu çalışmanın kısıtllı̆̆ı, kesitsel bir çalışma olmasıdır. Ek olarak, diğer otoimmün hastalıklar bu çalışmada klinik duruma göre saptanmıştır. Bilindiği üzere tiroid otoantikorlarının düzeyleri zaman içinde azalabilmektedir ama biz sadece yüksek düzeyleri değerlendirdik ${ }^{41}$.

Sonuç olarak, PBK tanısı alan her hasta tiroid hastalıkları bakımından incelenmelidir. Bu yaygın hastalığın her hastada taranması ve gerekliyse multidisipliner bir yaklaşımla tedavi edilmesi gereklidir. Çok yönlü tedavi hastaların yaşam kalitesini artırabilir. 
1. Culp KS, Fleming CR, Duffy J, Baldus WP, Dickson ER. Autoimmune associations in primary biliary cirrhosis. Mayo Clin Proc 1982;57:365.

2. Talwalkar JA, Lindor KD. Primary biliary cirrhosis. Lancet 2003; 362: 53-61.

3. Floreani A, Franceschet I, Cazzagon N, Spinazzè A, Buja A, Furlan P, Baldo, et al . Extrahepatic autoimmune conditions associated with primary biliary cirrhosis. Clin rev allergy immunol 2015; 48(2-3), 192-197.

4. Antonelli A, Ferrari SM, Corrado A, Di Domenicantonio A, Fallahi P. Autoimmune thyroid disorders. Autoimmun Rev 2015; 14(2):174-80.

5. Cardenas Roldan J, Amaya-Amaya J, Castellanos-de la Hoz J, Giraldo-Villamil J, Montoya-Ortiz G, Cruz-Tapias P, Rojas-Villarraga A, et al. Autoimmune thyroid disease in rheumatoid arthritis: a global perspective. Arthritis 2012; 2012:864907.

6. Crowe JP, Christensen E, Butler J. Primary biliary cirrhosis: the prevalence of hypothyroidism and its relationship to thyroid autoantibodies and sicca syndrome. Gastroenterology 1980; $78: 1437-41$.

7. Elta GH, Seperrsky RA, Goldberg MJ, Connors CM, Miller KB, Kaplan MM. Increased incidence of hypothyroidism in primary biliary cirrhosis . Dig Dis Sci $1982 ; 28: 971-5$

8. Silveira MG, Mendes FD, Diehl NN, Enders FT, Lindor KT, et al. Thyroid dysfunction in primary biliary circhosis, primary sclerosing cholangitis and non-alcoholic fatty liver disease . Liver Int $2009 ; 29$ : 1094 - 100

9. Kurihara Y, Shishido T, Oku K, Takamatsu M, Ishiguro H, Suzuki A, Sekita $T$, et all. Polymyositis associated with autoimmune hepatitis, primary biliary cirrhosis, and autoimmune thrombocytopenic purpura. Modern Rheumatol 2011; vol. 21, no. 3, pp. 325-329.

10. Bach $\mathrm{N}$ and Odin JA. Primary biliary cirrhosis: a Mount Sinai perspective. Mt Sinai J Med 2003; vol. 70, no. 4, pp. 242-250

11. Bittencourt PL, Farias AQ , Porta G, Cançado EL, Miura I, Pugliese R, Kalil $J$ et al. Frequency of concurrent autoimmune disorders in patients with autoimmune hepatitis: effect of age, gender, and genetic background. Journal of Clinical Gastroenterology 2008; vol. 42, no. 3, pp. 300-305.

12. Kmieciak Le Corguillé $M$, Rocher $P$, Eugène $C$, Lemaire $E$, Tennenbaum R, Vitte RL, Bergue A. Autoimmune hepatitis, acute pancreatitis, mixed connective tissue disease and Sjogren's syndrome. A case report. Gastroenterol Clin Biol 2003; vol. 27, no. 8-9, pp. 840-841.

13. Kaplan MJ, Ike RW. Theliver is a common non-exocrine target in primary Sjogren's syndrome: a retrospective review. BMC Gastroenterology 2002; vol. 2, article 21

14. EASL Clinical Practice Guidelines. Management of cholestatic liver diseases. J Hepatol 2009; 51: 237-67.

15. Garber JR, Cobin RH, Gharib H, Hennessey JV, Klein I, Mechanick JI, Pessah-Pollack R, et al. Clinical practice guidelines for hypothyroidism in adults: cosponsored by the American Association of Clinical Endocrinologists and the American Thyroid Association. Endocr Pract 2012; 18:988-1028.

16. Schever P. Primary biliary cirrhosis. Proc R Soc Med 1967 60:12571260

17. Caturegli P, De Remigis A, Rose NR . Hashimoto's thyroiditis: clinical and diagnostic criteria. Autoimmun Rev $2014 ; 13: 391-7$

18. Menconi $F$, Marcocci C , Marino M . Diagnosis and classifi cation of Graves' disease. Autoimmun Rev $2014 ; 13: 398-402$.

19. Punzi L, Betterle C. Chronic autoimmune thyroiditis and rheumatic manifestations. Joint Bone Spine 2004; 71(4):275-83.

20. Carlé A, Laurberg P, Knudsen N, Perrild H, Ovesen L, Rasmussen LB, Jorgensen $\mathrm{T}$, et al. Thyroid peroxidase and thyroglobulin auto-antibodie in patients with newly diagnosed overt hypothyroidism. Autoimmunity 2006; vol. 39, no. 6, pp. 497-503

21. Tunbridge WM, Brewis M, French JM, Appleton D, Bird T, Clark F, Evered $\mathrm{DC}$, et al. Natural history of autoimmune thyroiditis. Br Med J Clin Res Ed 1981; 282(6260), 258-262.

22. Vanderpump MP, Tunbridge WM, French JM, Appleton D, Bates D, Clark F, Grimley Evans J, et al. The incidence of thyroid disorders in the community: a twenty-year follow-up of the Whickham Survey. Clin Endocrinol $1995 ; 43(1), 55-68$
23. Prentice LM, Phillips DI, Sarsero D, Beever $K$, MclachlanSM, Smith BR Geographical distribution of subclinical autoimmune thyroid disease in Britain: a study using highly sen-sitive direct assays for autoantibodies to thyroglobulin and thyroid peroxidase. Acta Endocrinol 1990; 123(5), 493- 498 .

24. Floreani A, Mangini C, Reig A, Franceschet I, Cazzagon N, Perini L, Caballería $L$, et al. Thyroid dysfunction in primary biliary cholangitis: comparative study at two European centers. Am J Gastroenterol. 2017 Jan;112(1):114-119.

25. Watt FE, James OFW, Jones DEJ. Patterns of autoimmunity in primary biliary cirrhosis patients and their families: a population-based cohort study. QJM 2004;vol. 97, no. 7, pp. 397-406.

26. Parikh-Patel A, Gold EB, Worman H, Krivy KE, Gershwin ME. Risk factors for primary biliary cirrhosis in a cohort of patients from the United States. Hepatology 2001;33: 16-21

27. Plowden TC, Schisterman EF, Sjaarda LA, Zarek SM, Perkins NJ, Silver R, et al. Subclinical hypothyroidism and thyroid autoimmunity are not associated with fecundity, pregnancy loss or live birth. J Clin Endocrinol Metab 2016; 101(6):2358-65

28. Seror J, Amand G, Guibourdenche J, Ceccaldi PF, Luton D. Anti-TPO antibodies diffusion through the placental barrier during pregnancy. PLoS One 2014 Jan 31;9(1):e84647.

29. Wang GC, Talor MV, Rose NR, Cappola AR, Chiou RB, Weiss C, et al. Thyroid autoantibodies are associated with a reduced prevalence of frailty in community-dwelling older women. J Clin Endocrinol Metab 2010; 95:1161-8.

30. Prinzi N, Sorrenti S, Baldini E, De Vito C, Tuccilli C, Catania A, et al. Association of thyroid diseases with primary extra-thyroidal malignancies in women: results of a cross-sectional study of 6,386 patients. PLoS One 2015 Mar 31;10(3):e 0122958

31.31. Lambrinoudaki I, Armeni E, Pliatsika P, Rizos D, Kaparos G, Augoulea $A$, Alexandrou A, et all. Thyroid function and autoimmunity are associated with the risk of vertebral fractures in postmenopausal women. J Bone Miner Metab J Bone Miner Metab. 2017 Mar; 35(2):227-233.

32. Polovina SP, Miljic D, Zivojinovic S, Milic, N, Micic, D, Popovic Brkic V. The impact of thyroid autoimmunity (TPOAb) on bone density and fracture risk in postmenopausal women. Hormones (Athens) 2017; 16(1), 54-61.

33. Teufel A, Weinmann A, Kahaly GJ, Centner C, Piendl A, Worns M, Lohse $\mathrm{AV}$, et all. Concurrent autoimmune diseases in patients with autoimmune hepatitis. J Clin Gastroenterol 2010; 44:208-213

34. Hirschfield GM, Liu X, Xu C, Lu Y, Xie G, Lu Y, Gu X, et all. Primary biliary cirrhosis associated with HLA, IL12A, and IL12RB2 variants. New Eng Journal of Med 2009; 360(24), 2544- 2555.

35. Yan N, Meng S, Zhou J, Xu J, Muhali FS, Jiang W, Shi L. Association between STAT4 gene polymorphisms and autoimmune thyroid diseases in a Chinese population. Int j mol sci 2014; 15(7), 12280-12293.

36. Chistiakov DA, Turakulov RI. CTLA-4 and its role in autoimmune thyroid disease. J Mol Endocrinol 2003; 31(1):21-36.

37. Poupon R. Genetic factors of susceptibility and of severity in primary biliary cirrhosis. J Hepatol 2008; 49(6):1038-1045

38. Goldblatt J, Taylor PJ, Lipman T, Prince MI, Baragiotta A, Bassendine MF, James OF, et al. The true impact of fatigue in primary biliary cirrhosis: a population study. Gastroenterology 2002; 122(5), 1235-1241.

39. Elnady BM, Kamal NM, Shaker RH, Soliman AF, Hasan WA, Alghamdi HA, Algethami MM, et al. Prevalence and clinical significance of nonorgan specific antibodies in patients with autoimmune thyroiditis as predicto markers for rheumatic diseases. Medicine 2016; 95(38).

40. Peeva E. Reproductive immunology: a focus on the role of female sex hormones and other genderrelated factors. Clin Rev Allergy Immuno 2011; 40: 1-7

41. Bryhni B, Aanderud S, Sundsfjord J, Rekvig OP, Jorde R. Thyroid antibodies in northern Norway: prevalence, persistence and relevance. J Intern Med 1996; 239(6), 517-523
Sakarya Tıp Dergisi 2018;8(3):511-517
VATANSEVER ve Ark 